\title{
Cardiopulmonary changes induced by retroperitoneal insufflation in healthy dogs in sternal recumbency with the abdomen unsupported
}

\author{
Hyunglak SON ${ }^{1)}$, Jonghyeok KO ${ }^{1)}$, Junemoe JEONG ${ }^{2)}$, Sungin LEE ${ }^{1)}$, \\ Dongmin SIHN ${ }^{1)}$, Oh-Kyeong KWEON ${ }^{1)}$ and Wan Hee KIM ${ }^{1) *}$ \\ ${ }^{1)}$ Department of Veterinary Clinical Science, College of Veterinary Medicine and Research Institute for \\ Veterinary Science, Seoul National University, 1 Gwanak-ro, Gwanak-gu, Seoul 08826, Republic of Korea \\ ${ }^{2)}$ Department of Clinical Sciences, College of Veterinary Medicine, Oregon State University, Corvallis, Oregon, USA
}

\begin{abstract}
This study assessed the effects of retroperitoneal carbon dioxide $\left(\mathrm{CO}_{2}\right)$ insufflation on cardiopulmonary variables and intra-abdominal pressure (IAP) in mechanically ventilated dogs in sternal recumbency with the abdomen unsupported, following placement of a positioning kit and towels under the pectoral and pelvic regions. General anesthesia was induced in eight healthy adult male Beagles. A Swan-Ganz catheter was placed in the pulmonary artery via the jugular vein for cardiac output measurements. A Foley urethral catheter was placed to monitor transvesical IAP. A $10 \mathrm{~mm}$ balloon blunt-tip trocar was inserted into the retroperitoneal space. With a fixed respiratory rate and tidal volume by mechanical ventilation, insufflation pressure was sequentially increased from 0 to $10 \mathrm{mmHg}$ in $5 \mathrm{mmHg}$ increments, followed by desufflation. All variables were measured before insufflation, $5 \mathrm{~min}$ after the establishment of each insufflation pressure, and after

desufflation. At $10 \mathrm{mmHg}$, the IAP was nearly equal to insufflation pressure. Cardiopulmonary function was not compromised at any point, although the cardiac index $(\mathrm{Cl})$, heart rate, mean arterial pressure (MAP), and mean pulmonary arterial pressure increased within normal ranges. End-tidal $\mathrm{CO}_{2}$ concentration, arterial $\mathrm{CO}_{2}$ partial pressure, and oxygen delivery index $\left(\mathrm{DO}_{2} \mathrm{l}\right)$ increased, whereas $\mathrm{pH}$ decreased, at $10 \mathrm{mmHg}$. Cl, MAP, and $\mathrm{DO}_{2} \mathrm{I}$ did not recover to baseline after decompression. Thus, retroperitoneal $\mathrm{CO}_{2}$ insufflation up to $10 \mathrm{mmHg}$ is well tolerated by mechanically ventilated dogs positioned in sternal recumbency with the abdomen unsupported, although sympathetic changes may occur with an insufflation pressure increase.

KEY WORDS: cardiac output, cardiopulmonary changes, dog, retroperitoneal insufflation
\end{abstract}

J. Vet. Med. Sci.

82(1): 94-100, 2020

doi: 10.1292/jvms.19-0330

Received: 18 June 2019

Accepted: 30 October 2019

Advanced Epub:

3 December 2019

In human medicine, retroperitoneal laparoscopy has gained wide acceptance as a standard procedure for several surgeries ranging from excision of retroperitoneal organs to removal of ureteral calculi $[3,13,35]$. Unlike the transperitoneal approach, retroperitoneal laparoscopy facilitates direct visualization of and access to target organs, such as the adrenal glands, kidneys, and ureters, thus preventing physical interference by abdominal organs during procedures. The cardiopulmonary effects of retroperitoneal pressure in humans have been investigated in studies that compared the hemodynamic effects of intraperitoneal and retroperitoneal insufflation. Overall, no deleterious cardiovascular effects have been identified up to an insufflation pressure of $25 \mathrm{mmHg}$; moreover, the intra-abdominal pressure (IAP) is reported to increase by a considerably smaller margin, presumably because the retroperitoneal space is a confined space $[1,2,5,9,10]$. Similarly, other studies have shown that the impact of retroperitoneal insufflation on the ventilatory system is minimal, relative to that of transperitoneal insufflation [22, 25, 28].

A previous study in dogs evaluated the retroperitoneal approach and working space by increasing retroperitoneal pressure from 5 to $15 \mathrm{mmHg}$ in $5 \mathrm{mmHg}$ increments with carbon dioxide $\left(\mathrm{CO}_{2}\right)$ instillation into the retroperitoneum in combination with pressure-dependent space distention [16]. To maximize the gravitational retraction of the intraperitoneal organs, the authors of that study adopted the sternal position with the abdomen unsupported. In another study, total retroperitoneoscopic adrenalectomy was experimentally performed at a pressure of $5 \mathrm{mmHg}$ in healthy Beagle dogs [20]. However, these canine studies involving retroperitoneal insufflation did not document the cardiopulmonary changes induced by different insufflation pressures in the sternal position with the abdomen unsupported $[16,20]$. The characteristic retroperitoneal space development pattern at a low insufflation 
pressure $(\leq 15 \mathrm{mmHg})$ in dogs has not been observed in humans and pigs. In addition, previous hemodynamic studies in humans and other species involved evaluations at high insufflation pressures $(15-30 \mathrm{mmHg})$ in a variety of positions, including the jackknife position and the lateral position with table flexion $[5,8,10,22]$. Therefore, it can be inferred that different consequences might be observed in healthy dogs positioned in sternal recumbency with the abdomen unsupported.

Accordingly, the aim of the present study was to investigate the cardiopulmonary changes induced by different insufflation pressures during retroperitoneal insufflation in dogs positioned in sternal recumbency with the abdomen unsupported. The first hypothesis was that retroperitoneal insufflation in this position would not have a negative impact on the cardiopulmonary system in healthy dogs. The second hypothesis was that IAP would increase concurrently with retroperitoneal insufflation because of distention of the retroperitoneal space.

\section{MATERIALS AND METHODS}

\section{Animals}

Eight sexually intact, adult male Beagle dogs, aged $2.4 \pm 0.9$ years (mean \pm standard deviation [SD]; range, 1.0 to 4.0 years) and weighing $10.2 \pm 1.3 \mathrm{~kg}$ (mean $\pm \mathrm{SD}$; range, 8.8 to $11.7 \mathrm{~kg}$ ), were included in this study. No preexisting diseases or cardiopulmonary abnormalities were identified in any of the dogs based on medical history, physical examination, hematological and biochemical profiling, and thoracic radiography prior to the study. Food, but not water, was withheld for $12 \mathrm{hr}$ prior to premedication. The experimental protocol was approved by the Seoul National University Institutional Animal Care and Use Committee (SNU-181219-1).

\section{Anesthesia}

For each experiment, a 22-gauge catheter was aseptically placed in the cephalic vein, and lactated Ringer's solution was intravenously administered at a rate of $5 \mathrm{ml} / \mathrm{kg} / \mathrm{hr}$. Following premedication with intravenous (IV) tramadol (5 mg/kg), subcutaneous carprofen $(4.4 \mathrm{mg} / \mathrm{kg})$, and IV acepromazine $(0.01 \mathrm{mg} / \mathrm{kg})$, anesthesia was induced with alfaxalone $(5 \mathrm{mg} / \mathrm{kg} \mathrm{IV}$ to effect; Alfaxan ${ }^{\circledR}$, Jurox Inc., Kansas City, MO, USA). An appropriately sized endotracheal tube was placed, and the dogs were connected to a rebreathing anesthetic circuit. Anesthesia was maintained with isoflurane (Ifrane, Hana Pharm, Hwaseong, Republic of Korea) delivered in $100 \%$ oxygen at an end-tidal concentration of $1.8-1.9 \%$. The dogs were allowed to breath spontaneously until the end of the instrumentation period.

\section{Instrumentation and positioning}

The dogs were positioned in lateral recumbency on a table, after which the hair over the right jugular vein, dorsal pedal artery, and caudal aspect of the hemithorax and lateral abdomen was adequately clipped. The animals were subsequently moved to the operating room and positioned in lateral recumbency for aseptic scrubbing at the trocar and catheter insertion sites. An arterial catheter was placed in the dorsal pedal artery for arterial blood sampling and continuous invasive blood pressure monitoring. In addition, a 6 Fr, $12 \mathrm{~cm}$ introducer sheath (FAST-CATH hemostasis introducers, St. Jude Medical, Minnetonka, MN, USA) was simultaneously placed in the right jugular vein via the Seldinger technique. Three pressure transducers (Transpac IV Monitoring Kit, ICU Medical Inc., San Clemente, CA, USA), calibrated against a mercury manometer prior to each study, were connected to the arterial catheter, as well as the distal and proximal ports of the Swan-Ganz catheter, through saline-filled, noncompliant tubing. The pressure transducers were zeroed at the level of the sternum. A 5 Fr, $75 \mathrm{~cm}$ Swan-Ganz catheter (Edwards Lifesciences Corp., Irvine, CA, USA) was advanced through the sheath and placed in the pulmonary artery. The final position of the catheter tip was confirmed by characteristic pressure waveforms corresponding to the right ventricle and the pulmonary arterial occlusion pressure (PAOP) on inflation of the balloon located at the catheter tip. A multiparameter monitor (FI/Carescape Monitor B650, GE Healthcare, Helsinki, Finland), equipped with an agent analyzer, a side-stream capnograph, a pulse oximeter, and a spirometry module, displayed the heart rate (HR), respiratory rate (RR), tidal volume (TV), end-tidal carbon dioxide concentration $\left(\mathrm{ETCO}_{2}\right)$, end-tidal isoflurane concentration ( $\mathrm{ET}_{\mathrm{ISO}}$ ), mean arterial pressure (MAP), and central venous pressure (CVP). Hemoglobin (Hb) saturation and electrocardiograms were also monitored during general anesthesia. The thermistor on the Swan-Ganz catheter measured the core body temperature (BT), whereas the distal port of the catheter measured the mean pulmonary arterial pressure (PAP) and PAOP via another electronic monitor (Datex-Ohmeda S/5, GE Healthcare, Helsinki, Finland) with a cardiac output module (Datex-Ohmeda M-COP, GE Healthcare). During anesthesia, BT was maintained between $36^{\circ} \mathrm{C}$ and $38^{\circ} \mathrm{C}$ using warm water blankets (HTP-1500, Adroit Medical Systems, Loudon, TN, USA) and a warm air unit (Bair Hugger warming unit, model 505, Augustine Medical, Eden Prairie, MN, USA).

An 8 Fr Foley catheter (Foley catheter, Yushin Medical Corp., Seoul, Republic of Korea) was placed to maintain an empty bladder during general anesthesia and for transvesical measurement of IAP, in accordance with the Malbrain technique used in previous veterinary studies $[15,33]$. For each pressure measurement, the urinary bladder was evacuated and then filled with $1 \mathrm{~m} l /$ $\mathrm{kg}$ of $0.9 \%$ sodium chloride [33].

For repositioning of the dogs in sternal recumbency with the abdomen unsupported [16, 24], a commercial patient positioning kit (Vacu-positioner kit, Shor-line, Kansas City, KS, USA) was used and supplemental towels were placed under the pectoral and pelvic regions to ensure that the abdomen freely hung above the table (Fig. 1). For further position security, adhesive tape was minimally applied as necessary around the thorax and pelvic region. The three blood pressure transducers and the intraperitoneal pressure transducer were zeroed at the level of the right atrium and pubic symphysis, respectively. 


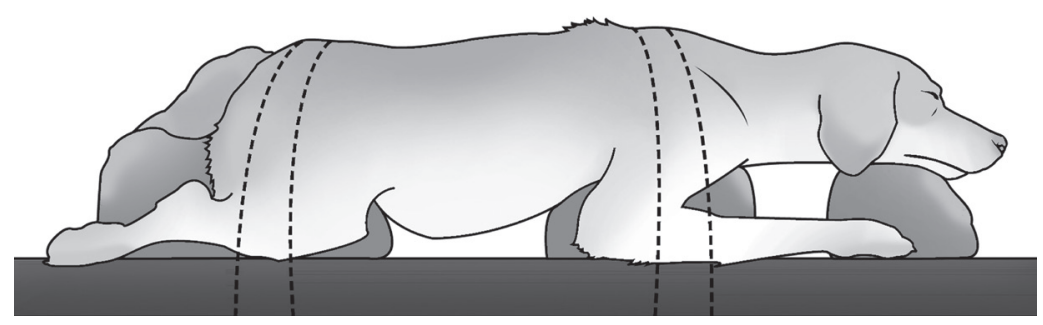

Fig. 1. Schematic presentation of a dog in sternal recumbency on the surgical table with abdomen unsupported by towels and positioning kit under the pectoral and pelvic areas.

For cardiac output measurement using the thermodilution method, $5 \%$ dextrose solution at a temperature of $0-4^{\circ} \mathrm{C}$ was rapidly and manually administered as a 5-m $l$ injectate into the proximal port of the Swan-Ganz catheter at the end of expiration [11]. At each time point, three values with $<10 \%$ variations among five consecutive measurements were chosen, and the average of these values was determined as the cardiac output. Arterial blood from the dorsal pedal artery and mixed venous blood from the distal port of the Swan-Ganz catheter were anaerobically collected in heparinized syringes at each time point. A blood gas analyzer (ABL-80 Flex, Radiometer America, Westlake, OH, USA) was used to measure the $\mathrm{pH}$ value, Hb concentration, partial pressure of carbon dioxide $\left(\mathrm{PaCO}_{2}\right)$, partial pressure of arterial oxygen $\left(\mathrm{PaO}_{2}\right)$, bicarbonate $\left(\mathrm{HCO}_{3}^{-}\right)$level, and base excess (BE) in these samples. Standard formulae [12] were used to acquire all derivative parameters, including the cardiac index (CI), stroke volume index (SI), systemic vascular resistance index (SVRI), pulmonary vascular resistance index (PVRI), dead space (DS), arterial oxygen content $\left(\mathrm{CaO}_{2}\right)$, oxygen delivery index $\left(\mathrm{DO}_{2} \mathrm{I}\right)$, oxygen consumption index $\left(\mathrm{VO}_{2} \mathrm{I}\right)$, and oxygen extraction ratio $(\mathrm{OER})$.

\section{Retroperitoneal trocar placement}

In accordance with the retroperitoneal access technique for dogs [16, 20], a $1.5 \mathrm{~cm}$ vertical incision site was created at the level of the second lumbar vertebrae on the right side in four dogs and the level of the third lumbar vertebrae on the left side in the other four dogs. Using Metzenbaum scissors in the dominant hand, with the index finger of the nondominant hand as a guide, blunt dissection was performed to the retroperitoneal space below the level of the epaxial muscle. When the dorsal margin of the kidney could be palpated with the index finger, a $10 \mathrm{~mm}$ inflatable balloon blunt-tip trocar with an adjustable sleeve (OMS-T10BT, Covidien, Dublin, Ireland) was placed into the retroperitoneal space. The balloon was inflated to prevent leakage of the insufflated gas and dislocation of the placed trocar. Subsequently, a $5 \mathrm{~mm} 0^{\circ}$ telescope (Karl Stortz, Tuttlingen, Germany) was advanced into the port to confirm the trocar tip within the retroperitoneal space through visualization of loose connective tissue mesh [16]. The telescope was removed after confirmation.

\section{Experimental procedure}

Mechanical ventilation was initiated after instrumentation was complete. Respiratory paralysis to facilitate ventilation was induced by atracurium injection $\left(0.2 \mathrm{mg} / \mathrm{kg} \mathrm{IV}\right.$ as the initial loading dose and $0.1 \mathrm{mg} / \mathrm{kg} \mathrm{IV}$ as needed). ETCO $\mathrm{ETas}_{2}$ maintained between 35 and $40 \mathrm{mmHg}$ using a volume-cycled ventilator (Vent-V, Royal Medical Co., Ltd., Seoul, Republic of Korea) with the following settings: RR, 15-20 breaths per minute; TV, $15 \mathrm{ml} / \mathrm{kg}$; inspiratory:expiratory ratio, 1:2; and peak airway pressure $\left(\mathrm{P}_{\mathrm{aw}}\right),<15 \mathrm{cmH}_{2} \mathrm{O}$. When the $\mathrm{ETCO}_{2}$ of each experiment was $>40 \mathrm{mmHg}$ before commencement of baseline data acquisition, we controlled the respiratory rate and maintained the tidal volume at $15 \mathrm{ml} / \mathrm{kg}$ with a maximum peak air way pressure of $<15 \mathrm{cmH}_{2} \mathrm{O}$ until the values were equilibrated. The dogs were then well ventilated and the target $\mathrm{ETCO}_{2}$ of 35 to $40 \mathrm{mmHg}$ was achieved. For each dog, the respiratory settings were fixed when $\mathrm{ETCO}_{2}$ was within the target range and the systemic blood pressure was stable. The dogs were then stabilized for $15 \mathrm{~min}$. After the equilibration period, baseline values were measured, and an electronic $\mathrm{CO}_{2}$ insufflator (Karl Stortz, Tuttlingen, Germany) was set to deliver $\mathrm{CO}_{2}$ at a rate of $1.0 \mathrm{l} / \mathrm{min}$. The mean retroperitoneal insufflation pressure was sequentially increased from 0 to $10 \mathrm{mmHg}$ in $5 \mathrm{mmHg}$ increments. Cardiopulmonary parameters and IAP were measured, in conjunction with acquisition of blood samples for arterial and mixed venous blood gas analysis 5 min after the establishment of each predefined pressure. Following measurements at $10 \mathrm{mmHg}$, the inflatable balloon trocar was opened, and the abdomen was gently compressed so that the infused gas could be purged out of the retroperitoneal space while maintaining sternal recumbency with an unsupported abdomen. Cardiopulmonary parameters were measured again 5 min post deflation.

\section{Postoperative care and pain management}

When the inflatable balloon trocar, pulmonary and peripheral arterial catheters, and introducer had been removed, incisions at the trocar and puncture sites were closed in a routine manner. Firm pressure was applied over the catheterized sites on the neck and hind limb to ensure hemostasis and prevent hematoma formation. Following the recovery of spontaneous respiration, IV neostigmine $(0.04 \mathrm{mg} / \mathrm{kg})$ and atropine $(0.04 \mathrm{mg} / \mathrm{kg})$ were administered to reverse neuromuscular paralysis. The dogs were extubated when a repetitive swallowing reflex was observed and were closely monitored after extubation. For pain control, oral analgesics (tramadol $5 \mathrm{mg} / \mathrm{kg}$, carprofen $2.2 \mathrm{mg} / \mathrm{kg}$ twice daily) were administered for 5 days. One investigator (DMS) used the 
Colorado State University Veterinary Medical Center Canine Acute Pain Scale [34] to assess postoperative pain at 1, 2, 4, 6, 12, and $24 \mathrm{hr}$ after tracheal extubation and once daily for the next 5 days. A pain score $\geq 2$ was considered an indication for rescue analgesia. Survey thoracic radiography was performed to check for a pneumomediastinum.

\section{Statistical analysis}

The normality of data distribution in terms of the pressures and approach side (right, left) was assessed using the Shapiro-Wilk test. One-way repeated measures analysis of variance (ANOVA) and the Mann-Whitney $U$ test were used to compare differences in normally distributed and non-normally distributed values at each pressure, respectively, between right and left sides. We found that the side did not affect cardiopulmonary values; therefore, this factor was excluded from further analysis. For parametric variables, one-way repeated measures ANOVA was used for comparisons among different insufflation pressures. When a significant effect was observed, values were compared using post hoc tests with Bonferroni correction. For nonparametric variables, Friedman repeated measures ANOVA was performed with post hoc pairwise Dunn-Bonferroni adjustment to identify significant differences among insufflation pressures. Based on the results of normality testing at each insufflation pressure, all parametric values are displayed as mean $\pm \mathrm{SD}$. The values of $\mathrm{mPAP}, \mathrm{PAOP}, \mathrm{ETCO}_{2}$ and $\mathrm{DO}_{2} \mathrm{I}$ were non-parametric; thus, these variables are presented as median [range]. All statistical analyses were performed using a commercial software package (IBM SPSS statistics version 22.0, IBM, Armonk, NY, USA). A $P$-value $<0.05$ was considered statistically significant.

\section{RESULTS}

All surgical procedures were completed without any complications, and no additional doses of atracurium were used during the study. All dogs exhibited an uneventful recovery from general anesthesia within $<150 \mathrm{~min}$. None of the dogs showed pneumomediastinum in survey thoracic radiography.

All data were acquired for all dogs. As mentioned above, the approach side did not affect the variables; therefore, further analyses excluded this aspect. The results are presented in Tables 1 and 2 . The mean BT ranged from 36.8 to $37.0^{\circ} \mathrm{C}$, and the $\mathrm{ET}_{\mathrm{ISO}}$ was constant at $1.7 \%$ throughout the study. The prescribed TV was maintained at $15 \mathrm{ml} / \mathrm{kg}$, while the average RR was fixed at 18 \pm 2 breaths per min throughout the measurement period. Consequently, mean minute ventilation remained virtually unchanged from the baseline value, at $2.74 \mathrm{l} / \mathrm{min}$ during the study period. The IAP remained unchanged at $5 \mathrm{mmHg}$ and exhibited a significant increase at $10 \mathrm{mmHg}(9.3 \pm 1.0 \mathrm{mmHg}$ at $10 \mathrm{mmHg}$ versus $5.1 \pm 0.6 \mathrm{mmHg}$ at baseline; $P<0.001)$. At $5 \mathrm{mmHg}$, none of the cardiovascular variables other than MAP $(P=0.037)$ showed a significant change relative to baseline. At $10 \mathrm{mmHg}, \mathrm{CI}, \mathrm{HR}, \mathrm{MAP}$, mPAP, and PAOP were significantly higher than their respective baseline values $(P=0.008, P=0.01, P=0.004, P<0.001, P=0.006$, respectively). Among these variables, $\mathrm{CI}$, MAP, and $\mathrm{mPAP}(P=0.006, P=0.021, P=0.012$, respectively $)$ remained elevated after desufflation, with significant differences from their respective baseline values. SVRI, PVRI, and SI showed no significant changes during and after insufflation.

Regarding the pulmonary variables, no significant changes were observed at a pressure of $5 \mathrm{mmHg}$. At $10 \mathrm{mmHg}, \mathrm{ETCO}_{2}$, $\mathrm{PaCO}_{2}$, and $\mathrm{DO}_{2} \mathrm{I}$ exhibited significant increases $(P=0.003, P=0.016, P<0.001$, respectively), while the $\mathrm{pH}$ exhibited a significant decrease $(P=0.042)$. The $\mathrm{DO}_{2} \mathrm{I}$ remained high after desufflation $(P=0.012)$. The other parameters, namely $\mathrm{PaO}_{2}, \mathrm{Hb}, \mathrm{CaO}_{2}, \mathrm{VO}_{2} \mathrm{I}$, OER, $\mathrm{P}_{\mathrm{aw}}$, systemic respiratory compliance, and dead space, showed no significant changes during and after insufflation.

\section{DISCUSSION}

Both hypotheses in the present study were accepted; a retroperitoneal insufflation pressure of $\leq 10 \mathrm{mmHg}$ did not compromise cardiopulmonary function in mechanically ventilated healthy dogs positioned in sternal recumbency with the abdomen unsupported. Although the hemodynamic changes were observed during the retroperitoneal insufflation, all values remained within normal reference ranges. Insufflation at $10 \mathrm{mmHg}$ increased the transvesically measured IAP to a near-equivalent value. The mechanical impact on the pulmonary system was minimal, with an increase in $\mathrm{PaCO}_{2}$ observed with an increase in retroperitoneal insufflation pressure.

We found that the IAP at baseline and at an insufflation pressure of $5 \mathrm{mmHg}$ were nearly the same, whereas the IAP at 10 $\mathrm{mmHg}$ was significantly elevated. According to previous studies, the normal IAP measured using the transvesical method ranges from 0 to $7 \mathrm{mmHg}$ in dogs $[15,32]$, which was similar to the baseline value of IAP in this study. Changes in both the IAP and retroperitoneal pressure returned to baseline after gas removal. In humans, retroperitoneal insufflation up to $15 \mathrm{mmHg}$ resulted in no change in transvesical IAP, with higher pressures $(20-24 \mathrm{mmHg})$ inducing a small pressure increase $(3.0 \mathrm{mmHg})$ from baseline [10]. Similarly, the IAP increased from 0 to $3 \mathrm{mmHg}$ during retroperitoneal insufflation at $15 \mathrm{mmHg}$ in pigs [2]. The contrasting findings in humans and pigs could be attributed to the retroperitoneal fascial compartmentalization, which restricts distention of the retroperitoneal space by simple $\mathrm{CO}_{2}$ insufflation tracking along the fascial planes and, presumably, prevents pressure transmission from the retroperitoneal cavity. Indeed, surgeons require special balloon devices for initial distention of this potential space [1, 6, $10,19]$. However, the canine retroperitoneum does not have fascial compartments, does not work as a pressure buffer, and seems to be more compliable, thus enabling $\mathrm{CO}_{2}$ insufflation at pressures $\leq 15 \mathrm{mmHg}$ to create a potential space in a pressure-dependent manner $[16,17]$.

In the present study, an insignificant increase in SI combined with a significant increase in HR may have raised the CI at an insufflation pressure of $10 \mathrm{mmHg}$ and after gas removal. During the study, HR, SI, MAP, and mPAP exhibited an increasing trend 
Table 1. Relationship between insufflation pressure and cardiovascular variables during retroperitoneal insufflation in healthy dogs $(n=8)$ positioned in sternal recumbency with the abdomen unsupported

\begin{tabular}{|c|c|c|c|c|}
\hline Parameter & Preinsufflation & $5 \mathrm{mmHg}$ & $10 \mathrm{mmHg}$ & Desufflation \\
\hline $\mathrm{ET}_{\text {ISO }}(\%)$ & $1.7 \pm 0.1$ & $1.7 \pm 0.1$ & $1.7 \pm 0.1$ & $1.7 \pm 0.1$ \\
\hline IAP (mmHg) & $5.1 \pm 0.6$ & $5.0 \pm 1.2$ & $9.3 \pm 1.0^{\mathrm{a})}$ & $5.4 \pm 0.9$ \\
\hline $\mathrm{CI}\left(\mathrm{l} / \mathrm{min} / \mathrm{m}^{2}\right)$ & $4.1 \pm 0.8$ & $4.7 \pm 0.7$ & $5.5 \pm 0.8^{\mathrm{a})}$ & $5.3 \pm 0.6^{\mathrm{a})}$ \\
\hline $\mathrm{SI}(\mathrm{m} l / \mathrm{kg})$ & $1.7 \pm 0.4$ & $1.9 \pm 0.3$ & $2.1 \pm 0.4$ & $2.0 \pm 0.3$ \\
\hline HR (beats/min) & $115 \pm 9$ & $120 \pm 10$ & $127 \pm 11^{\mathrm{a})}$ & $126 \pm 15$ \\
\hline MAP (mmHg) & $71 \pm 9$ & $80 \pm 11^{\text {a) }}$ & $94 \pm 10^{\mathrm{a})}$ & $83 \pm 12^{\mathrm{a})}$ \\
\hline CVP (mmHg) & $2.6 \pm 1.3$ & $2.6 \pm 2.1$ & $3.4 \pm 1.5$ & $2.8 \pm 0.7$ \\
\hline mPAP (mmHg) & $14.5[12.0-15.0]$ & $15.0[12.0-19.0]$ & $17.0[14.0-21.0]^{\mathrm{a})}$ & $18.0[13.0-20.0]^{\mathrm{a})}$ \\
\hline PAOP (mmHg) & $6.5[6.0-9.0]$ & $7.5[6.0-11.0]$ & $9.0[6.0-12.0]^{\mathrm{a})}$ & $8.0[5.0-10.0]$ \\
\hline SVRI (dynes $\cdot \mathrm{sec} / \mathrm{cm}^{5} \cdot \mathrm{m}^{2}$ ) & $1,369 \pm 237$ & $1,329 \pm 241$ & $1,325 \pm 108$ & $1,219 \pm 163$ \\
\hline PVRI (dynes $\cdot \mathrm{sec} / \mathrm{cm}^{5} \cdot \mathrm{m}^{2}$ ) & $144 \pm 46$ & $128 \pm 45$ & $123 \pm 41$ & $135 \pm 40$ \\
\hline $\mathrm{BT}\left({ }^{\circ} \mathrm{C}\right)$ & $37.0 \pm 0.7$ & $36.9 \pm 0.6$ & $37.0 \pm 0.6$ & $36.8 \pm 0.4$ \\
\hline
\end{tabular}

Data are expressed as mean \pm standard deviation (SD) or median [range]. a) Within a row, values significantly differ $(P<0.05)$ from the respective preinsufflation values. $\mathrm{BT}$, body temperature; $\mathrm{CI}$, cardiac index; $\mathrm{CVP}$, central venous pressure; $\mathrm{ET}_{\text {ISO }}$, end-tidal isoflurane concentration; HR, heart rate; IAP, intra-abdominal pressure; MAP, mean arterial pressure; mPAP, mean pulmonary arterial pressure; PAOP, pulmonary arterial occlusion pressure; PVRI, pulmonary vascular resistance index; SI, stroke volume index; SVRI, systemic vascular resistance index.

Table 2. Relationship between insufflation pressure and pulmonary variables during retroperitoneal insufflation in healthy dogs $(n=8)$ positioned in sternal recumbency with the abdomen unsupported

\begin{tabular}{lcccc}
\hline \multicolumn{1}{c}{ Parameter } & Preinsufflation & $5 \mathrm{mmHg}$ & $10 \mathrm{mmHg}$ & Desufflation \\
\hline $\mathrm{P}_{\mathrm{aw}}\left(\mathrm{cmH}_{2} \mathrm{O}\right)$ & $11.8 \pm 1.8$ & $11.9 \pm 1.7$ & $12.4 \pm 1.8$ & $11.6 \pm 1.8$ \\
$\mathrm{CL}\left(\mathrm{m} l / \mathrm{cm} \mathrm{H} \mathrm{H}_{2} \mathrm{O}\right)$ & $17.9 \pm 3.0$ & $17.6 \pm 3.1$ & $16.5 \pm 3.6$ & $18.5 \pm 3.8$ \\
$\mathrm{PaO}_{2}(\mathrm{mmHg})$ & $543 \pm 54$ & $574 \pm 54$ & $578 \pm 47$ & $583 \pm 33$ \\
$\mathrm{ETCO}_{2}(\mathrm{mmHg})$ & $37.0[35-40]$ & $36.5[35-43.5]$ & $42[38-47]^{\mathrm{a})}$ & $39.5[36-43.8]$ \\
$\mathrm{PaCO}_{2}(\mathrm{mmHg})$ & $43.8 \pm 3.9$ & $44.5 \pm 7.0$ & $48.7 \pm 5.6^{\mathrm{a})}$ & $46.9 \pm 6.0$ \\
$\mathrm{MV}(l / \mathrm{min})$ & $2.74 \pm 0.31$ & $2.74 \pm 0.31$ & $2.72 \pm 0.30$ & $2.77 \pm 0.32$ \\
$\mathrm{Dead} \mathrm{space}$ & $14.0 \pm 6.5$ & $12.7 \pm 7.0$ & $12.6 \pm 5.1$ & $14.1 \pm 4.5$ \\
$\mathrm{Blood} \mathrm{pH}$ & $7.32 \pm 0.03$ & $7.32 \pm 0.05$ & $7.29 \pm 0.04^{\mathrm{a})}$ & $7.3 \pm 0.04$ \\
$\mathrm{HCO}{ }^{-}(\mathrm{mmol} / l)$ & $21.8 \pm 1.4$ & $22.2 \pm 1.7$ & $22.6 \pm 1.1$ & $22.3 \pm 1.31$ \\
$\mathrm{BE}(\mathrm{mmol} / l)$ & $-3.6 \pm 1.1$ & $-3.5 \pm 1.4$ & $-3.6 \pm 1.0$ & $-3.8 \pm 1.0$ \\
$\left.\mathrm{Hb}^{\mathrm{g}} / \mathrm{d} l\right)$ & $10.4 \pm 1.5$ & $9.8 \pm 1.3$ & $10.3 \pm 1.2$ & $10.3 \pm 1.4$ \\
$\mathrm{CaO}_{2}(\mathrm{~m} l / \mathrm{d} l)$ & $16.0 \pm 2.0$ & $15.3 \pm 1.7$ & $16.0 \pm 1.6$ & $16.0 \pm 1.9$ \\
$\mathrm{DO}_{2} \mathrm{I}\left(\mathrm{m} l / \mathrm{min} / \mathrm{m}^{2}\right)$ & $644[528-743]$ & $694[666-744]$ & $\left.838[778-986]^{\mathrm{a}}\right)$ & $805[763-864]^{\mathrm{a})}$ \\
$\mathrm{VO}_{2} \mathrm{I}\left(\mathrm{m} l / \mathrm{min} / \mathrm{m}^{2}\right)$ & $77 \pm 29$ & $55 \pm 28$ & $63 \pm 20$ & $70 \pm 13$ \\
$\mathrm{OER}(\%)^{\mathrm{Da}}$ & $11.8 \pm 3.4$ & $7.5 \pm 3.7$ & $7.3 \pm 2.4$ & $8.2 \pm 1.5$ \\
\hline
\end{tabular}

Data are expressed as mean \pm standard deviation (SD) or median [range]. a) Within a row, values significantly differ $(P<0.05)$ from the respective preinsufflation values. $\mathrm{BE}$, base excess; $\mathrm{CaO}_{2}$, arterial oxygen content; $\mathrm{CL}$, systemic respiratory compliance; $\mathrm{DO}_{2} \mathrm{I}$, oxygen delivery; $\mathrm{ETCO}_{2}$, end-tidal carbon dioxide; $\mathrm{Hb}$, hemoglobin; $\mathrm{HCO}_{3}^{-}$, bicarbonate concentration; $\mathrm{MV}$, minute ventilation; OER, oxygen extraction ratio; $\mathrm{PaCO}_{2}$, partial pressure of arterial carbon dioxide; $\mathrm{PaO}_{2}$, partial pressure of arterial oxygen; $\mathrm{P}_{\mathrm{aw}}$, peak airway pressure; $\mathrm{VO}_{2} \mathrm{I}$, oxygen consumption.

with an increase in retroperitoneal pressure. Although changes in cardiovascular variables initiated at a pressure of $5 \mathrm{mmHg}$, the IAP did not change. Moreover, CI, MAP and mPAP remained significantly elevated after decompression, with insignificant increases in SI, HR, and recovery of IAP to baseline. Thus, the mechanical impact of retroperitoneal insufflation seemed limited.

Another possible etiology could be sympathetic activity associated with the pain response or hypercarbia [7, 23, 27]. Nociceptive stimulation during laparoscopy is thought to be related to surgical manipulation of the visceral organs or stretching of the abdominal muscles $[26,29,30]$. Although the visceral organs were not manipulated throughout the study, retroperitoneal insufflation in dogs causes abdominal distention in terms of height and width in healthy dogs as pressure increases [16], presumably stimulating the sympathetic system. A study in humans also showed that an increasing retroperitoneal insufflation pressure without surgical intervention may have caused sympathetic stimulation, with an increase in HR and MAP, but they considered mild hypercarbia and light depth of anesthesia rather than abdominal distention as the sources of sympathetic stimulation [8]. In the present study, the $\mathrm{ET}_{\text {ISO }}$ value remained unchanged throughout the measurement period. Moreover, during the instrumentation period, surgical stress, including catheterization and trocar placement, did not induce a pain response in terms of increases in HR, MAP, and RR in the study dogs. However, the inadequate depth of anesthesia during insufflation remains problematic due to the lack of opioid analgesics and fixed level of inhalant anesthesia. 
Notably, $\mathrm{PaCO}_{2}$ in our dogs increased by only $0.7 \mathrm{mmHg}$ at a lower pressure, whereas it increased by approximately $5 \mathrm{mmHg}$ at a higher pressure. Another canine study involving laparoscopy documented comparable increases in $\mathrm{PaCO}_{2}$ with no increase in $\mathrm{HR}$ [14], whereas other studies in dogs [4] and cats [32] attributed an increase in HR to reflex tachycardia for the compensation of a decreased stroke volume and maintenance of the cardiac output, which was not observed in the current study. [4, 31].

Sympathetic tone contributes to vessel constriction; however, a relevant increase in the vascular resistance was not observed in the present study, likely due to vascular tone being determined by a multitude of factors, such as the insufflation pressure, type of anesthetic gas, $\mathrm{PaCO}_{2}$ level, and neurohumoral regulation during laparoscopy $[18,27]$. Previous studies in humans have reported varied responses in terms of the systemic and pulmonary vascular tones during retroperitoneal insufflation [8, 9]. We also identified significant increases in PAOP. This change reflected a centrally redistributed blood volume or increased intrathoracic pressure transmitted from the retroperitoneal space. Both factors may have contributed to changes in our experiment, given that insignificant increases in SI and $\mathrm{P}_{\mathrm{aw}}$ were confirmed in all dogs. The findings in other human studies $[8,10]$ showed that increases in CVP and PAOP were associated with increased venous return and an increased physical impact of insufflation on ventilation.

Regarding respiratory function, we fixed the ventilator settings for RR and TV throughout the measurement period to determine the mechanical impact of insufflation on respiratory function and maintain normocarbia prior to obtaining measurements. Although trends regarding increased $\mathrm{P}_{\mathrm{aw}}$ and decreased systemic lung compliance existed during insufflation, both of which were reversible after decompression, the magnitude of pressure transmission in the study dogs seemed clinically negligible and was not statistically significant. In contrast, $\mathrm{P}_{\mathrm{aw}}$ increased significantly in humans at pressures (e.g., $12-15 \mathrm{mmHg}$ ) achieved with fixed ventilator settings; this was thought to result from anatomical sharing of the cranial border of the retroperitoneal space with the dorsal border of the diaphragm $[22,25]$. Minute ventilation was constant, with no increase in $\mathrm{DS}$ and $\mathrm{VO}_{2} \mathrm{I}$ throughout the study period. Therefore, the trend for a $\mathrm{PaCO}_{2}$ increase with respiratory acidosis primarily originated from direct absorption through the retroperitoneum. Considering that $\mathrm{CO}_{2}$ absorption in a body cavity is determined by its diffusibility and the perfusion capability of the cavity walls $[8,21]$, the insufflation pressure-dependent increase in $\mathrm{PaCO}_{2}$ can be attributed to enlargement of the retroperitoneal space, which increases the absorptive surface area. Oxygenation was well maintained as $\mathrm{PaO}_{2}$ and $\mathrm{DO}_{2} \mathrm{I}$ did not decrease at any point. Alterations in $\mathrm{DO}_{2} \mathrm{I}$ paralleled the changes in CI at a pressure of $10 \mathrm{mmHg}$ and after desufflation. As $\mathrm{DO}_{2} \mathrm{I}$ is a product of $\mathrm{CI}$ and $\mathrm{CaO}_{2}$, a significant increase in $\mathrm{CI}$ increased $\mathrm{DO}_{2} \mathrm{I}$ because $\mathrm{CaO}_{2}$ was not affected by any insufflation pressure.

The cardiopulmonary effects of retroperitoneal insufflation were not influenced by the approach side (left and right), although these findings may have resulted from type two statistical errors due to the small number of dogs included. However, recruiting more dogs into each group is not likely to induce clinically different physiological consequences based on the approach side because the dogs were positioned in sternal rather than lateral recumbency. A previous canine study showed that retroperitoneal space volumes were not significantly different with right and left approaches at pressures of 5 and $10 \mathrm{mmHg}$ [16]. A study in humans reported that the approach side did not affect the hemodynamic consequences and resulted in subtle differences without clinical relevance [10].

This study had several limitations. First, the sequence of insufflation pressures could not be randomized because insufflation enlarges the retroperitoneal space, and a high pressure followed by a low pressure may affect the cardiopulmonary results. Second, the equilibration period for each insufflation pressure was only $5 \mathrm{~min}$; therefore, the cardiopulmonary effects at a fixed retroperitoneal insufflation pressure for a prolonged period may be different. Finally, all dogs included in this study had no cardiopulmonary diseases or other pathologies. Thus, veterinarians must exercise caution when extrapolating the study findings to dogs with cardiopulmonary diseases.

In summary, our findings suggest that retroperitoneal insufflation up to $10 \mathrm{mmHg}$ does not induce detrimental cardiopulmonary effects and is well-tolerated in mechanically ventilated healthy dogs positioned in sternal recumbency with the abdomen unsupported. Cardiostimulatory activity may be observed during retroperitoneal insufflation; this becomes more evident at higher pressures. Therefore, maintenance of a low retroperitoneal pressure $(5 \mathrm{mmHg})$ could aid in stabilization of the cardiovascular system, and meticulous intraoperative management of anesthesia during insufflation may be necessary with higher pressure (10 $\mathrm{mmHg}$ ). Further studies should elaborate on the causes of sympathetic stimulation during retroperitoneal insufflation in sternal recumbency with the abdomen unsupported.

ACKNOWLEDGMENT. This research was supported by the Bio \& Medical Technology Development Program of the National Research Foundation (NRF) funded by the Ministry of Science, ICT \& Future Planning (2016M3A9B6026771).

\section{REFERENCES}

1. Callender, G. G., Kennamer, D. L., Grubbs, E. G., Lee, J. E., Evans, D. B. and Perrier, N. D. 2009. Posterior retroperitoneoscopic adrenalectomy. Adv. Surg. 43: 147-157. [Medline] [CrossRef]

2. Chiu, A. W., Chang, L. S., Birkett, D. H. and Babayan, R. K. 1995. The impact of pneumoperitoneum, pneumoretroperitoneum, and gasless laparoscopy on the systemic and renal hemodynamics. J. Am. Coll. Surg. 181: 397-406. [Medline]

3. Constantinides, V. A., Christakis, I., Touska, P. and Palazzo, F. F. 2012. Systematic review and meta-analysis of retroperitoneoscopic versus laparoscopic adrenalectomy. Br. J. Surg. 99: 1639-1648. [Medline] [CrossRef]

4. Duke, T., Steinacher, S. L. and Remedios, A. M. 1996. Cardiopulmonary effects of using carbon dioxide for laparoscopic surgery in dogs. Vet. Surg. 25: 77-82. [Medline] [CrossRef]

5. Fernández-Cruz, L., Saenz, A., Benarroch, G., Astudillo, E., Taura, P. and Sabater, L. 1996. Laparoscopic unilateral and bilateral adrenalectomy for Cushing's syndrome. Transperitoneal and retroperitoneal approaches. Ann. Surg. 224: 727-734, discussion 734-736. [Medline] [CrossRef] 
6. Fraser, S., Norlén, O., Bender, K., Davidson, J., Bajenov, S., Fahey, D., Li, S., Sidhu, S. and Sywak, M. 2018. Randomized trial of low versus high carbon dioxide insufflation pressures in posterior retroperitoneoscopic adrenalectomy. Surgery 163: 1128-1133. [Medline] [CrossRef]

7. Gerges, F. J., Kanazi, G. E. and Jabbour-Khoury, S. I. 2006. Anesthesia for laparoscopy: a review. J. Clin. Anesth. 18: 67-78. [Medline] [CrossRef]

8. Giebler, R. M., Walz, M. K., Peitgen, K. and Scherer, R. U. 1996. Hemodynamic changes after retroperitoneal $\mathrm{CO}_{2}$ insufflation for posterior retroperitoneoscopic adrenalectomy. Anesth. Analg. 82: 827-831. [Medline]

9. Giebler, R. M., Kabatnik, M., Stegen, B. H., Scherer, R. U., Thomas, M. and Peters, J. 1997. Retroperitoneal and intraperitoneal $\mathrm{CO}_{2}$ insufflation have markedly different cardiovascular effects. J. Surg. Res. 68: 153-160. [Medline] [CrossRef]

10. Giebler, R. M., Behrends, M., Steffens, T., Walz, M. K., Peitgen, K. and Peters, J. 2000. Intraperitoneal and retroperitoneal carbon dioxide insufflation evoke different effects on caval vein pressure gradients in humans: evidence for the starling resistor concept of abdominal venous return. Anesthesiology 92: 1568-1580. [Medline] [CrossRef]

11. Haskins, S. 2012. Cardiac output monitoring. pp. 159-176. In: Advanced Monitoring and Procedures for Small Animal Emergency and Critical Care, 1st ed. (Creedon, J. M. B. and Davis, H. eds.), John Wiley \& Sons, Chichester.

12. Haskins, S., Pascoe, P. J., Ilkiw, J. E., Fudge, J., Hopper, K. and Aldrich, J. 2005. Reference cardiopulmonary values in normal dogs. Comp. Med. 55: 156-161. [Medline]

13. He, B., Bremner, A., Han, Y. and Hamdorf, J. M. 2016. Determining the superior technique for living-donor nephrectomy: The laparoscopic intraperitoneal versus the retroperitoneoscopic approach. Exp. Clin. Transplant. 14: 129-138. [Medline]

14. Ivankovich, A. D., Miletich, D. J., Albrecht, R. F., Heyman, H. J. and Bonnet, R. F. 1975. Cardiovascular effects of intraperitoneal insufflation with carbon dioxide and nitrous oxide in the dog. Anesthesiology 42: 281-287. [Medline] [CrossRef]

15. Jang, M., Son, W. G., Jo, S. M., Kim, H., Shin, C. W. and Lee, I. 2018. A novel balloon technique to induce intra-abdominal hypertension and its effects on cardiovascular parameters in a conscious dog model. J. Vet. Emerg. Crit. Care (San Antonio) 28: 326-333. [Medline] [CrossRef]

16. Jeong, J., Ko, J., Lim, H., Kweon, O. K. and Kim, W. H. 2016. Retroperitoneal laparoscopy in dogs: Access technique, working space, and surgical anatomy. Vet. Surg. 45 S1: O102-O110. [Medline] [CrossRef]

17. Johnston, D. E. and Christie, B. A. 1990. The retroperitoneum in dogs: Anatomy and clinical significance. Comp. Cont. Educ. Pract. 12: 1027-1033.

18. Kaklamanos, I. G., Condos, S. and Merrell, R. C. 2000. Time-related changes in hemodynamic parameters and pressure-derived indices of left ventricular function in a porcine model of prolonged pneumoperitoneum. Surg. Endosc. 14: 834-838. [Medline] [CrossRef]

19. Keeley, F. X. Jr. and Tolley, D. A. 1999. Retroperitoneal laparoscopy. BJU Int. 84: 212-215. [Medline] [CrossRef]

20. Ko, J., Jeong, J., Lee, S., Son, H., Kweon, O. K. and Kim, W. H. 2018. Feasibility of single-port retroperitoneoscopic adrenalectomy in dogs. Vet. Surg. 47 S1: O75-O83. [Medline] [CrossRef]

21. Lister, D. R., Rudston-Brown, B., Warriner, C. B., McEwen, J., Chan, M. and Walley, K. R. 1994. Carbon dioxide absorption is not linearly related to intraperitoneal carbon dioxide insufflation pressure in pigs. Anesthesiology 80: 129-136. [Medline] [CrossRef]

22. Lorenzo, A. J., Karsli, C., Halachmi, S., Dolci, M., Luginbuehl, I., Bissonnette, B. and Farhat, W. A. 2006. Hemodynamic and respiratory effects of pediatric urological retroperitoneal laparoscopic surgery: a prospective study. J. Urol. 175: 1461-1465. [Medline] [CrossRef]

23. Marcovich, R., Williams, A. L., Seifman, B. D. and Wolf, J. S. Jr. 2001. A canine model to assess the biochemical stress response to laparoscopic and open surgery. J. Endourol. 15: 1005-1008. [Medline] [CrossRef]

24. Naan, E. C., Kirpensteijn, J., Dupré, G. P., Galac, S. and Radlinsky, M. G. 2013. Innovative approach to laparoscopic adrenalectomy for treatment of unilateral adrenal gland tumors in dogs. Vet. Surg. 42: 710-715. [Medline] [CrossRef]

25. Nadu, A., Ekstein, P., Szold, A., Friedman, A., Nakache, R., Cohen, Y., Matzkin, H. and Weinbroum, A. A. 2005. Ventilatory and hemodynamic changes during retroperitoneal and transperitoneal laparoscopic nephrectomy: a prospective real-time comparison. J. Urol. 174: $1013-1017$. [Medline] [CrossRef]

26. Park, Y. T. and Okano, S. 2015. Influence of pneumoperitoneum and postural change on the cardiovascular and respiratory systems in dogs. J. Vet. Med. Sci. 77: 1223-1226. [Medline] [CrossRef]

27. Rasmussen, J. P., Dauchot, P. J., DePalma, R. G., Sorensen, B., Regula, G., Anton, A. H. and Gravenstein, J. S. 1978. Cardiac function and hypercarbia. Arch. Surg. 113: 1196-1200. [Medline] [CrossRef]

28. Sasagawa, I., Suzuki, H., Izumi, T., Shoji, N., Nakada, T., Takaoka, S., Miura, Y., Hoshi, H., Amagasa, S. and Horikawa, H. 1999. Influence of carbon dioxide on respiratory function during posterior retroperitoneoscopic adrenalectomy in prone position. Eur. Urol. 36: 413-417. [Medline] [CrossRef]

29. Sato, N., Kawamoto, M., Yuge, O., Suyama, H., Sanuki, M., Matsumoto, C. and Inoue, K. 2000. Effects of pneumoperitoneum on cardiac autonomic nervous activity evaluated by heart rate variability analysis during sevoflurane, isoflurane, or propofol anesthesia. Surg. Endosc. 14: 362-366. [Medline] [CrossRef]

30. Scott, J. E., Singh, A., Valverde, A., Blois, S. L., Foster, R. A., Kilkenny, J. J. and Linden, A. Z. 2018. Effect of pneumoperitoneum with warmed humidified or standard-temperature carbon dioxide during laparoscopy on core body temperature, cardiorespiratory and thromboelastography variables, systemic inflammation, peritoneal response, and signs of postoperative pain in healthy mature dogs. Am. J. Vet. Res. 79: 1321-1334. [Medline] [CrossRef]

31. Shih, A. C., Case, J. B., Coisman, J. G., Isaza, N. M., Amora-Junior, D. and Maisenbacher, H. W. 3rd. 2015. Cardiopulmonary effects of laparoscopic ovariectomy of variable duration in cats. Vet. Surg. 44 Suppl 1: 2-6. [Medline] [CrossRef]

32. Smith, S. E. and Sande, A. A. 2012. Measurement of intra-abdominal pressure in dogs and cats. J. Vet. Emerg. Crit. Care (San Antonio) 22: 530-544. [Medline] [CrossRef]

33. Way, L. I. and Monnet, E. 2014. Determination and validation of volume to be instilled for standardized intra-abdominal pressure measurement in dogs. J Vet Emerg Crit Care (San Antonio) 24: 403-407. [Medline] [CrossRef]

34. Wiese, J. A. 2015. Assessing pain. pp. 67-97. In: Handbook of Veterinary Pain Management, 3rd ed. (Gaynor, J. S. and Muir, W. W. 3rd. eds.), Elsevier, St. Louis.

35. Wu, Y., Dong, Q., Han, P., Liu, L., Wang, L. and Wei, Q. 2012. Meta-analysis of transperitoneal versus retroperitoneal approaches of laparoscopic pyeloplasty for ureteropelvic junction obstruction. J. Laparoendosc. Adv. Surg. Tech. A 22: 658-662. [Medline] [CrossRef] 